\title{
Analisa Pola Sesar Di Daratan Selatan Sumatera Berdasarkan Event Gempa Tahun 1960-2000
}

\author{
A. M. Miftahul Huda ${ }^{1 *}$, Badrul Munir ${ }^{2}$ \\ ${ }^{I}$ STT Migas Balikpapan \\ ${ }^{2}$ UIN Maulana Malik Ibrahim Malang \\ *mustafid13@gmail.com
}

\begin{abstract}
Fault pattern analysis has been done for southern Sumatera region through analysis of seismic data. The seismic data used is ISC data and combined with focal data from Global CMT from 1960-2000. This research was conducted in three stages, namely the determination of seismicity distribution, the determination of moment tensor through focal data, and correlation of data with geological data. At 1040-1060 BT geographical position there were 7 significant earthquakes throughout 1960 to 2000, including 3 strike slip fault, 1 reverse fault, 1 normal fault and 2 oblique faults. Anomaly of data occurred at seismicity from 1960-2000, namely observation of oblique fault. Seismic activity is influenced by Sumatera fault activity from Andaman to Semangko.
\end{abstract}

Keywords: fault pattern, tectonic activity, oblique fault

\begin{abstract}
Abstrak
Analisa pola sesar telah dilakukan untuk wilayah sumatera bagian selatan melalui analisis data kegempaan. Data kegempaan yang digunakan adalah data ISC dan dikombinasikan dengan data fokal dari Global CMT dari tahun 1960-2000. Penelitian ini dilakukan dalam tiga tahap, yaitu penentuan persebaran kegempaan, penentuan moment tensor melalui data fokal, dan korelasi data dengan data geologi. Pada posisi geografis $104^{0}-106^{0} \mathrm{BT}$ terdapat 7 gempa signifikan sepanjang tahun 1960 sampai tahun 2000, diantaranya 3 sesar mendatar (strike slip fault), 1 sesar naik (reverse fault), 1 sesar turun (normal fault) dan 2 sesar oblique. Anomali data terjadi pada seismisitas kegempaan tahun 1960-2000, yaitu teramatinya sesar oblique. Aktifitas kegempaan dipengaruhi oleh aktifitas sesar Sumatera dari Andaman sampai Semangko.
\end{abstract}

Kata kunci: pola sesar, gempa tektonik, fokal, oblique

\section{Pendahuluan}

Indonesia merupakan negara kepulauan dan memiliki zona unik akibat sejarah pembentukannya. Indonesia pada dasarnya terbentuk oleh beberapa lempeng aktif, tepatnya tiga lempeng besar dan sembilan lempeng kecil dengan jalur yang sangat kompleks. Akibatnya adalah Indonesia menjadi wilayah dengan aktivitas tektonik yang tinggi dan memberikan efek rawan terhadap bencana (tektonik) [1,2].

Beberapa penelitian telah dilakukan untuk mempelajari keunikan dari Indonesia. Jika dilihat dari keunikan tektoniknya, masingmasing wilayah di Indonesia memiliki keunikan tersendiri. Salah satu yang menarik perhatian dari para peneliti adalah wilayah barat Indonesia, khususnya wilayah Pulau Sumatera. Beberapa yang menarik perhatian adalah bencana tsunami, yang melanda Sumatera bagian Barat tahun 2004 dan gempa tektonik yang mengakibatkan korban jiwa di Lampung [2].

Aktifitas kegempaan yang intens di pulau Sumatera merupakan implikasi geodinamika dari deformasi aktif disekitar Sunda dan Java trench[3]. Kejadian gempa yang terjadi didekat batas pertemuan antara lempeng samudera yang menunjam masuk ke bawah lempeng benua diklasifikasikan sebagai 
zona subduksi. Zona subduksi Sumatera terbentang dari Selat Sunda ke arah utara hingga laut Andaman [2].

Mengingat morfologi Sumatera bagian selatan terbagi menjadi tiga komponen. Yakni, komponen dataran rendah yang berada di bagian timur dan timur laut, komponen pegunungan di bagian tengah dan barat daya, komponen perbukitan yang bergelombang di bagian tengah dan sedikit berada di bagaian selatan. Sumatera bagian selatan secara morfologi dapat dibagi menjadi tiga bagian, satuan daratan rendah dibagian timur dan timur laut, satuan pegunungan di bagian tengah dan barat daya, satuan perbukitan bergelombang di bagian tengah dan sedikit di bagian selatan. Secara umum Sumatera Selatan sudah dipengaruhi oleh proses tektonik, hal ini dicerminkan oleh bentuk morfologi yang beraneka ragam mulai dari daratan sampai perbukitan dan tersusun oleh beberapa jenis batuan [4].

Indonesia menempati zona tektonik yang sangat aktif karena tiga lempeng besar dunia dan sembilan lempeng kecil lainnya saling bertemu di wilayah Indonesia dan membentuk jalur-jalur pertemuan lempeng yang kompleks [1]. Keberadaan interaksi antar lempeng-lempeng ini menempatkan wilayah Indonesia sebagai wilayah yang sangat rawan terhadap gempa bumi. Gempa-gempa bumi yang terjadi di Pulau Sumatera merupakan implikasi geodinamika dari deformasi aktif disekitar Sunda dan Java trench [3]. Kejadian gempa yangterjadi didekat batas pertemuan antara lempeng samudra yangmenunjam masuk ke bawah lempeng benua diklasifikasikan sebagai zona subduksi. Zona subduksi Sumatera terbentang dariSelat Sunda ke arah utara hingga laut Andaman[4].

Penelitian ini dimaksudkan untuk mendapatkan informasi pola sesar yang berada di wilayah Sumatera bagian selatan. Harapannya adalah penelitian ini mampu memberikan pengetahuan tentang Pulau Sumatera bagian selatan dari segi tektonik dan tingkat resikonya, sehingga mampu menjadi early warning jika terjadi resiko bencana yang tinggi.

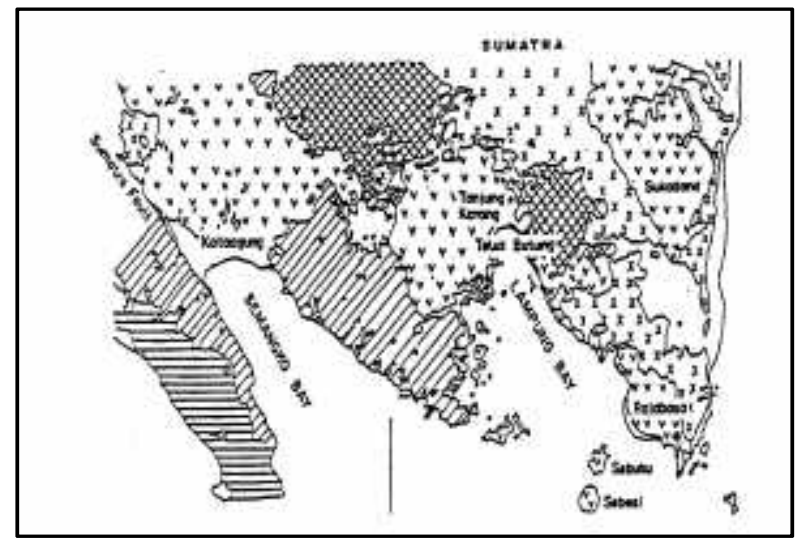

Gambar 1. Litologi Sumatera bagian selatan

\section{Metoda Penelitian}

Data penelitian didapatkan dari pusat data katalog kegempaan dari International Seismology Center (ISC) dan data fokal dari Global Centroid-Moment-Tensor (Global CMT). Data yang digunakan dibatasi pada event kegempaan antara tahun 1960-2000 dan pada wilayah penelitian, yaitu di sekitar wilayah Lampung, dengan koordinat batas penelitian antara $6^{0}$ LU- $6^{0}$ LS dan $102^{\circ}$ BT$107^{0} \mathrm{BT}$.

Akuisisi data dilakukan dengan merequest data secara online. Request dapat dilakukan ketika sudah ter-registrasi. Datadata yang didapatkan kemudian diproses melalui tiga tahap: pertama dilakukan pengolahan data catalog gempa untuk mendapatkan sebaran seismisitas dari wilayah penelitian; kedua, dilakukan penentuan focal mechanism melalui data ISC dan Global CMT, dan pemetaan geologi; ketiga, dilakukan visualisai data fokal menggunakan perangkat Generic Mapping Tool (GMT). Data ISC berisikan magnitude, tahun terjadinya gempa, beserta koordinat wilayah kegempaan. Data Global CMT berisikan bola fokal, strike, dip, slip, serta rake. 


\section{Hasil Penelitian}

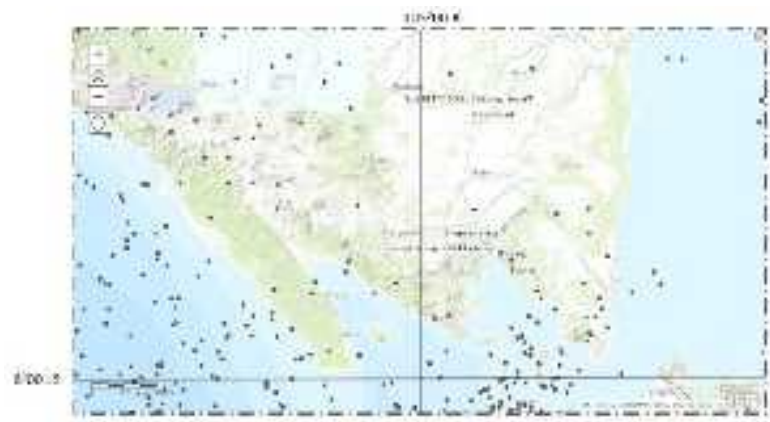

Gambar 2. Sebaran seismisitas di wilayah Provinsi Lampung tahun 1960-2000

Gambar 2 memperlihatkan pemusatan pemusatan gempa di sepanjang tepi Teluk Lampug yang bertepatan dengan garis sesar Lampung-Panjang, terdapat pula pusat gempa yang terletak di lepas pantai yang kemungkinan besar berhubungan dengan lajur Sesar Semangko dan struktur ikutannya. Sedangkan wilayah sebelah barat Provinsi Lampung yang pemusatan gempa bumi bertepatan dengan lajur penunjaman. Pusat gempa tersebut terletak pada kedalaman antara 0-60 km, dengan magnitude diatas $4 \mathrm{SR}$. Gempa tersebut berlangsung dengan lajur penunjaman yang ada sekarang. Peristiwa kegempaan terjadi di sepanjang garis lemah di tepi benua yang ditafsirkan sebagai zona batuan alas benua yang tersebar luas secara regional dan mungkin berlanjut ke bawah sampai di lajur penunjaman, akibatnya letak kegiatan seismik dan magmatik tersebar di sepanjang tepi benua.

Gempa pada wilayah posisi geografis $104^{0}-106^{0}$ BT terdapat 7 gempa signifikan sepanjang tahun 1960 sampai tahun 2000, diantaranya 3 sesar mendatar (strike slip fault), 1 sesar naik (reverse fault), 1 sesar turun (normal fault) dan 2 sesar oblique sebagaimana terlihat pada Gambar 3. Sesar geser yang dominan berada di daratan Provinsi Lampung tersebut dipengaruhi oleh Sistem Sesar Sumatera yang membelah daratan Sumatera dimulai dari Laut Andaman di sebelah Utara Aceh sampai di Teluk Semangko di selatan Sumatera.

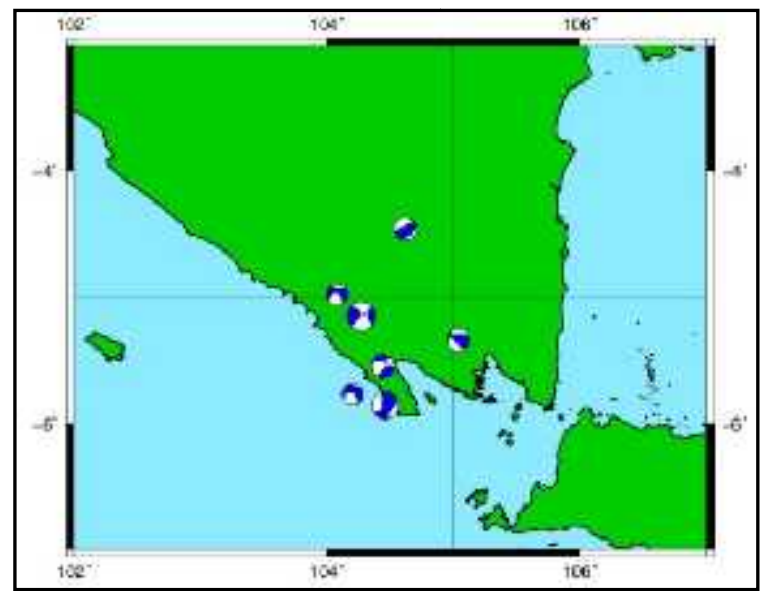

Gambar 3. Persebaran Focal Mechanism di daratan Sumatera bagian selatan

Tabel 1. Hasil Pengolahan Data Bola Fokal wilayah Provinsi Lampung

\begin{tabular}{|c|c|c|c|}
\hline Bujur & $\begin{array}{l}\text { Bola } \\
\text { Fokal }\end{array}$ & Jenis Sesar & Jumlah \\
\hline \multirow{4}{*}{$\begin{array}{c}102^{0}-107^{0} \\
\text { BT }\end{array}$} & & $\begin{array}{c}\text { Sesar geser } \\
\text { /sesar mendatar } \\
\text { (strike slip) }\end{array}$ & 3 \\
\hline & & $\begin{array}{l}\text { sesar naik } \\
\text { (reverse fault) }\end{array}$ & 1 \\
\hline & & $\begin{array}{l}\text { sesar turun } \\
\text { ( normal fault) }\end{array}$ & 1 \\
\hline & & sesar oblique & 2 \\
\hline
\end{tabular}

Analisa fokal(Tabel 1) menunjukkan adanya perbedaan terkait sesar oblique berorientasi baratdaya-tenggara yang didapatkan di wilayah barat pada lembar geologi Tanjungkarang sedangkan pada data geologi bidang cross section A-B-C terdapat sesar naik. Menurut data Global CMT pada koordinat 5,34 LS dan 105,04 BT menunjukkan terjadinya gempa dengan moment tensor sesar oblique, sehingga diinterpretasikan bahwasanya pada koordinat tersebut adalah sesar oblique, hal ini karena tidak ditemukannya kesesuaian data seismisitas pada tahun 1960-2000 yang merupakan sesar naik. Dominasi strike-slip sesuai dengan laporan dari tim revisi peta gempa Indonesia, dan banyaknya aktifitas kegempaan diwilayah sumatera dipengaruhi oleh megathrust southern Sumatra [5]. 
Selain gempa bumi yang dirasakan tersebut, pada area ini juga mendapatkan bahaya gunung api dan tsunami mengingat daerah selatan lembar ini sangat aktif dalam tektonik dan kegunung-apian.

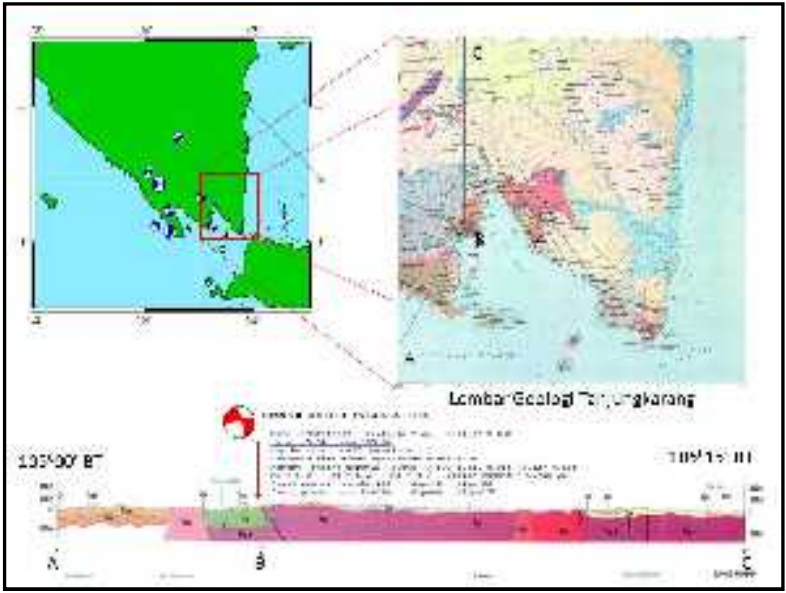

Gambar 4. Lembar Geologi Tanjungkarang beserta Moment Tensor

Gambar 4 merupakan cuplikan lembar geologi Tanjungkarang. Sejarah strukur Lembar Tanjungkarang meliputi peristiwa peristiwa tektonik sejak Paleozoikum Akhir sampai Resen. Tetapi Unsur-Unsur utama, yaitu sesar dan lipatan, dikuasai oleh Tektonika Tersier Akhir-Kuartel Awal. Pola kompleks sesar-sesar yang teramati dan kelurusan potret geologi yang terdapat di lembar ini diduga sesar-sesar tersebut tidak dapat berasal dari satu lapangan tegangan saja akan tetapi terdapat dua arah tegangan utama selama masa akhir Tersier. Pemampatan yang berarah utara-selatan bertanggung jawab atas gerakan menganan disepanjang sesar baratlauttenggara (dan gerakan mengiri disepanjang sesar-sesar timurlaut-baratdaya). Pemampatan yang berarah timur-barat bertanggung jawab atas sesar berbalik baratlaut-tenggara yang terjadi kemudian[6]. Untuk sementara dapat diduga bahwa lapangan tegangan di Sumatera telah berubah, semula berarah utara-selatan kemudian berubah menjadi timur-barat. Tetapi waktu yang pasti terjadinya perubahan tersebut belum dapat ditentukan dan masih memerlukan studi rinci lebih lanjut, namun gerakan-gerakan awal sementara ditafsirkan berumur Oligo-Miosen dan yang kemudian berumur Plio-Plistosen.

\section{Kesimpulan}

Kondisi geologis yang dipengaruhi oleh aktivitas tektonik tinggi di wilayah sumatera bagian selatan, mengakibatkan aktivitas kegempaan yang beragam. Peneliti menemukan bahwasanya sistem persesaran dipengaruhi oleh aktivitas sesar Sumatera dari Laut Andaman sampai Teluk Semangko. Sesar oblique dapat teramati meskipun pada data seismisitas tidak teramati. Wilayah Sumatera Selatan ini termasuk dalam kawasan rentan bencana alam kegempaan, sehingga penelitian ini dapat dilanjutkan dengan menambahkan data analisa fokal yang terjadi pada wilayah tersebut, supaya data yang didapatkan menjadi lebih lengkap dan rencana mitigasi dapat dilakukan secara optimal.

\section{Saran}

Sumatera bagian selatan dengan aktivitas seismik yang tinggi memungkinkan dampak bencana yang luas, oleh karenanya investigasi menyeluruh diperlukan untuk melengkapi bagian-bagian informasi yang telah dilakukan peneliti. Informasi struktur lokal diperlukan untuk menyeragamkan variebel pemrosesan data, sekaligus acuan untuk melakukan pebaikan proses selanjutnya.

\section{Daftar Pustaka}

[1] P. Bird, "An updated digital model of plate boundaries," Geochemistry, Geophys. Geosystems, vol. 4, no. 3, 2003.

[2] D. H. Natawidjaja, "Gempabumi dan Tsunami di Sumatra dan Upaya Untuk Mengembangkan Lingkungan Hidup yang Aman Dari Bencana Alam," Lap. KHL, LIPI, Jakarta, 2007.

[3] R. S. Yeats, K. E. Sieh, C. R. Allen, and E. L. Geist, The geology of earthquakes, vol. 568. Oxford university press New York, 1997.

[4] P. P. dan P. G. (Indonesia) and S. A. Mangga, Peta Geologi Lembar Tanjungkarang, Sumatera 1: 250,000. 
Pusat Penelitian dan Pengembangan Geologi, 1993.

[5] T. R. P. G. Indonesia, "Ringkasan Hasil Studi Tim Revisi Peta Gempa Indonesia 2010." Bandung, 2010.

[6] M. T. Holder, "Tertiary and quaternary Tectonics of the Barisan Mountains of Southern," Bandung, 1990. 